\title{
Absence of Thermal Hyperalgesia in Serotonin Transporter-Deficient Mice
}

\author{
Carola Vogel, ${ }^{1}$ Rainald Mössner, ${ }^{2}$ Manfred Gerlach, ${ }^{2}$ Thoralf Heinemann, ${ }^{2}$ Dennis L. Murphy, ${ }^{3}$ Peter Riederer, ${ }^{2}$ \\ Klaus-Peter Lesch, ${ }^{2}$ and Claudia Sommer ${ }^{1}$ \\ Departments of ${ }^{1}$ Neurology and ${ }^{2}$ Psychiatry and Psychotherapy, University of Würzburg, 97080 Würzburg, Germany, and ${ }^{3}$ Laboratory of Clinical Science, \\ National Institute of Mental Health, National Institutes of Health, Bethesda, Maryland 20892
}

Antidepressants in the treatment of neuropathic pain are thought to partially exert their effect by inhibition of serotonin (5-HT) reuptake and thus activation of central antinociceptive pathways. Mice deficient for the 5-HT transporter (5-HTT-l- mice) are regarded as a model of lifelong treatment with a serotonin reuptake inhibitor. Here we investigated 5-HTT $-1-$ mice and compared their pain-related behavior after a unilateral chronic constrictive sciatic nerve injury (CCI) with that of wild-type littermates. Wild-type mice reproducibly developed ipsilateral thermal hyperalgesia and mechanical allodynia after CCI. 5-HTT-I- mice did not develop thermal hyperalgesia, but showed bilateral mechanical allodynia after the nerve injury. 5-HT levels as measured with HPLC increased after CCI in the injured nerve in both genotypes and decreased in the lumbar spinal cord in wild-type mice. 5-HTT- - mice had significantly lower 5-HT concentrations than wild-type mice in all tissues investigated. Thus, in 5-HTT- $/-$ mice, reduced 5-HT levels in the injured peripheral nerves correlate with diminished behavioral signs of thermal hyperalgesia, a pain-related symptom caused by peripheral sensitization. In contrast, bilateral mechanical allodynia, a centrally mediated phenomenon, was associated with decreased spinal 5-HT concentrations in 5 -HTT - I- mice and may possibly be caused by a lack of spinal inhibition.

Key words: serotonin; serotonin transporter-deficient mice; hyperalgesia; allodynia; neuropathy; chronic constriction injury

\section{Introduction}

Serotonin [5-hydroxtryptamine (5-HT)] is present in serotonergic neurons, is released from platelets and mast cells after tissue injury, and exerts algesic and analgesic effects, depending on the site of action and on receptor subtype activation (for review, see Eide and Hole, 1993). The antinociceptive action of tricyclic antidepressant drugs (TCAs), which are widely used in neuropathic pain, has been at least in part attributed to inhibition of 5-HT reuptake via the 5-HT transporter (5-HTT) and to the potentiation of 5-HT neurotransmission and thus activation of central antinociceptive pathways (Eschalier et al., 1994). Other modes of action of TCAs are the blockade of sodium channels, opioidergic effects, and an antagonism at the NMDA receptor (Eschalier et al., 1994; Gerner et al., 2001). In the search for antidepressants with fewer adverse effects, selective 5-HT reuptake inhibitors [selective serotonin reuptake inhibitors (SSRIs)] were developed. In contrast to classical antidepressant drugs with additional effects on noradrenaline reuptake, they selectively inhibit the presynaptic reuptake of 5-HT through the 5-HTT. To date, only a few SSRIs have been proven effective for neuropathic pain in clinical trials (Sindrup et al., 1990, 1992). Furthermore, animal studies using TCA as well as selective serotonergic drugs show variable effects in different pain models (Abad et al., 1989; Seltzer et al.,

Received Sept. 3, 2002; revised Nov. 1, 2002; accepted Nov. 1, 2002.

This work was supported by the Volkswagenstiftung (C.V., C.S.) and by a grant from the Deutsche Forschungsgemeinschaft (SFB581, Z2 to M.G./P.R. and B9 to R.M./K.P.L.). We thank L. Biko, H. Brünner, and I. Fischer for technical assistance, K. Toyka for critical reading of this manuscript and helpful suggestions, and A. Spahn for help with the statistical analysis.

Correspondence should be addressed to Dr. Claudia Sommer, Neurologische Klinik der Universität, JosefSchneider-Strasse 11, 97080 Würzburg, Germany. E-mail: sommer@mail.uni-wuerzburg.de.

Copyright $\odot 2003$ Society for Neuroscience $\quad 0270-6474 / 03 / 230708-08 \$ 15.00 / 0$
1989; Ardid and Guilbaud, 1992; Lang et al., 1996; Esser and Sawynok, 1999; Sawynok et al., 1999; Wang et al., 1999). In several recent studies, a peripheral site of action of the antidepressants was demonstrated (Abdi et al., 1998; Sawynok et al., 1999), possibly indicating a peripheral role of 5-HT after nerve injury. After nerve transection, the 5-HT content in the lesioned nerve is increased (Anden and Olsson, 1967). 5-HT receptors of the $5-\mathrm{HT}_{3}$ and $5-\mathrm{HT}_{2 \mathrm{~A}}$ subtypes are present on $\mathrm{C}$ fibers (Fozard, 1984; Carlton and Coggeshall, 1997), and 5-HT, acting in combination with other inflammatory mediators, may ectopically excite and sensitize acutely axotomized afferent nerve fibers (Michaelis et al., 1997, 1998).

Mice with a deficiency in 5-HTT (5-HTT-/- mice) are considered to be a model of lifelong SSRI treatment (Bengel et al., 1998; Lesch and Heils, 2000). In the CNS, they have increased extracellular 5-HT levels, but the overall tissue content of 5-HT is reduced. The 5-HT receptors $5-\mathrm{HT}_{1 \mathrm{~A}}, 5-\mathrm{HT}_{1 \mathrm{~B}}$, and $5-\mathrm{HT}_{2 \mathrm{~A}}$ are downregulated in these mice (Rioux et al., 1999; Fabre et al., 2000). Here we used 5-HTT-/ - mice and a model of an experimental mononeuropathy to investigate further the role of 5-HT in neuropathic pain. The animals' pain-related behavior was correlated with changes in 5-HT content at different levels of the nervous system after peripheral nerve injury. We hypothesized that concomitant with an altered 5-HT content, 5-HTT-/mice would display altered pain-related behavior compared with wild-type mice.

\section{Materials and Methods}

Animals. Experiments were performed on 47 adult (4-7 months of age, 21-30 gm body weight) female mice of the C57BL/6J background. They included 26 wild-type $(5-\mathrm{HTT}+/+)$ and 21 homozygous knock-out (5HTT-/-) mice. The genotype was determined according to Bengel et al. 
(1998). The animals were housed on a 14/10 hr light/dark cycle with standard rodent chow and water available ad libitum. All experiments were approved by the Bavarian state authorities and performed in accordance with the European Communities Council Directive of November 24, 1986 (86/609/EEC) for the care and use of laboratory animals.

Surgery. Under deep barbiturate anesthesia, a chronic constrictive injury (CCI) of one sciatic nerve was performed in 30 mice as described by Bennett and Xie (1988), with minor modifications (Sommer and Schäfers, 1998). Three ligatures (7-0 Prolene) were placed around the sciatic nerve proximal to the trifurcation with $1 \mathrm{~mm}$ spacing, and tied until they just slightly constricted the diameter of the nerve and a brief twitch was seen in the respective hindlimb; a total of 17 unoperated animals served as controls.

Behavioral testing and measurement of skin temperature. Testing of different sensory modalities and of skin temperature was performed on 3 consecutive days before CCI and at regular intervals thereafter and accordingly in controls. Only two tests were performed on the same day: the measurement of skin temperature concomitantly with the testing of heat sensitivity and the assessment of mechanical sensitivity with the testing of cold sensitivity. The first day served to adapt the animals to the testing procedure. Mean values from the next $2 \mathrm{~d}$ of testing were taken as a mean to determine the baseline. Animals were sitting within a clear Plexiglas cage on a glass plate (for thermal testing) or on a metal mesh floor and were allowed to acclimatize for at least $5 \mathrm{~min}$ before recording. The sequence of the different tests, which were performed at least $30 \mathrm{~min}$ apart, was always the same, as were the time of testing and the testing room with a temperature of $25 \pm 0.5^{\circ} \mathrm{C}$. The experimenter was kept unaware of the animals' genotype. Individual animals were excluded from the final analysis if the values of repetitive tests differed by $\geq 100 \%$.

Sensitivity to noxious heat was assessed using the device of Hargreaves et al. (1988), purchased from Ugo Basile (Comerio, Italy). A radiant heat source was focused on the plantar surface of the hindpaw; the time from the initiation of the radiant heat until paw withdrawal was measured automatically [paw-withdrawal latency (PWL)]. A maximal cutoff of 20 sec was used to prevent tissue damage. Each paw was tested five times, alternating between paws with an interval of at least 1 min between tests; the mean withdrawal latency was calculated. The interval between two trials on the same paw was at least $5 \mathrm{~min}$. A significant decrease in the mean withdrawal latency after CCI compared with the baseline was defined as heat hyperalgesia.

Mechanical sensitivity was determined by probing the plantar surface of the hindpaw with calibrated von Frey hairs with circular plain tips of $0.8 \mathrm{~mm}$ diameter made from nylon filaments. The force required to bend the hairs ranged from 0.07 to $5.5 \mathrm{gm}$. Hairs were applied six times each on the basis of the up-and-down method of Dixon (1965), according to Chaplan et al. (1994) and modified for mice (Sommer and Schäfers, 1998). The time interval between two trials was at least 1 min on the same paw and at least $30 \mathrm{sec}$ on the alternate paw. The $50 \%$ withdrawal threshold (i.e., force of the von Frey hair to which an animal reacts in $50 \%$ of the presentations) was recorded. A significant decrease in the $50 \%$ withdrawal threshold after CCI compared with the baseline was termed mechanical allodynia.

Cold stimulation of the animals' hindpaws was performed according to the method of Choi et al. (1994), modified for mice (Vogel et al., 2000). A drop of acetone was formed at the end of a polyethylene tube with a tip diameter of $0.8 \mathrm{~mm}$ connected with a syringe and gently applied at the plantar aspect of the hindpaw. A drop of water from a similar tube with a temperature of $37^{\circ} \mathrm{C}$ served as a control. A response to acetone was defined as sharp withdrawal of the hindpaw lasting $>1 \mathrm{sec}$. Very brief withdrawals lasting $<1 \mathrm{sec}$ were assigned a value of 0 because they could be occasionally induced by a drop of water, whereas longer withdrawal times were typically a response to acetone and were never observed after the application of water. The paw elevation time was measured with a digital stopwatch from the onset of the paw withdrawal until the paw was rested again for at least $2 \mathrm{sec}$. The acetone was applied three times on each paw, and the mean of three trials was calculated. Repetitive testing was performed with an interval of at least $5 \mathrm{~min}$ for the same paw and of at least $1 \mathrm{~min}$ for the contralateral paw. Cold allodynia was defined as a
Table 1. Mean baseline values for heat, mechanical, and cold thresholds and skin temperature in $5-\mathrm{HTT}+/+$ and $5-\mathrm{HTT}-/-$ mice

\begin{tabular}{lcrr}
\hline & $5-\mathrm{HTT}+/+$ & 5 -HTT$-/-$ & $p$ value \\
\hline PWL to heat (seconds) & $8.1 \pm 0.5(12)$ & $8.5 \pm 0.6(12)$ & $>0.05$ \\
Mechanical 50\% threshold (grams) & $3.1 \pm 0.4(13)$ & $3.2 \pm 0.5(11)$ & $>0.05$ \\
$\begin{array}{l}\text { Paw withdrawal time to acetone } \\
\quad \text { seconds) }\end{array}$ & $0.3 \pm 0.3(12)$ & $0.5 \pm 0.4(11)$ & $>0.05$ \\
Skin temperature $\left({ }^{\circ} \mathrm{C}\right)$ & $33.7 \pm 1.2(10)$ & $32.8 \pm 1.3(10)$ & $>0.05$
\end{tabular}

Data are pooled for both sides in the individual animal and determined as a mean \pm SEM over all of the animals tested (numbers of animals in parentheses).

significant increase in postoperative paw withdrawal time to acetone of individual animals compared with their baseline.

A noncontact infrared thermometer (GTH 1200, Raynger IP; Greisinger, Regenstauf, Germany) with an inner diameter of $0.4 \mathrm{~cm}$ was used to assess the skin temperature of the plantar surface of the animals' hindpaws. After a 15-30 min adaptation, the skin temperature was recorded if it was stable for at least $10 \mathrm{sec}$. Three consecutive temperature determinations on each paw were performed with an interval of 1-10 min between each determination, and the means were calculated. To detect skin temperature changes after CCI, difference scores were evaluated by subtracting the temperature of the control side contralateral to CCI from the nerve-injured side. A positive difference score indicates that the nerve-ligated paw is warmer than the control side, whereas a negative difference score indicates that the ligated paw is cooler than the control paw. The presence of skin temperature asymmetry was defined on an individual basis as a significant deviation of the difference score from baseline at any postoperative day.

Determination of 5-HT and 5-hydroxyindolacetic acid concentrations. After decapitation under deep barbiturate anesthesia, tissue was harvested from operated animals on day 28 after CCI and from controls. Samples were taken from the plantar skin of the hindpaw with a size of $\sim 4 \times 6 \mathrm{~mm}$, from the sciatic nerve with a length of $1 \mathrm{~cm}$ (cut shortly cranial to the most proximal ligature and just proximally to the trifurcation and at respective sites in control nerves), from the $\mathrm{L} 4 / 5$ spinal cord (cut just proximally to the L4 and distally to the L 5 spinal root), and from the adrenal glands. Samples were weighed and frozen at $-70^{\circ} \mathrm{C}$. For HPLC, samples were sonicated under argon in ice-cold $150 \mathrm{~mm} \mathrm{H}_{3} \mathrm{PO}_{4}$ and $500 \mu \mathrm{M}$ diethylenetriamine pentaacetic acid and centrifuged at $35,000 \times g$ for $20 \mathrm{~min}$ at $4^{\circ} \mathrm{C}$. The supernatant was filtered through Millipore (Bedford, MA) Ultrafree-MC filter cups at $9000 \times g$ for $1-2 \mathrm{hr}$ at $4^{\circ} \mathrm{C}$. For the analysis of 5-HT and 5-hydroxyindolacetic acid (5HIAA), $50 \mu$ l portions of the supernatants were injected directly into an HPLC system with electrochemical detection (Gynkotek, Germering, Germany). The investigator was kept unaware of the animals' genotype.

Statistical analysis. For statistical analysis, the Statistical Program for the Social Sciences (version 10.0; SPSS, Chicago, IL) was used. Results are presented as means \pm SEM. To compare behavioral data between groups and test days, a two-way repeated-measures ANOVA was used for parametric analysis, followed by a Student's $t$ test. For nonparametric analysis of the von Frey thresholds, a Mann-Whitney $U$ test was used for comparison of data between groups; a Friedman test was used for comparison of data between test days within a group, followed by a Wilcoxon test. A $\chi^{2}$ test was used to compare groups at individual test days. Two-way ANOVA and Student's $t$ test for post hoc analysis permitted comparison of HPLC data between the groups and test days. A paired Student's $t$ test was used to compare between two means in the same subject. Significance was assumed at $p<0.05$.

\section{Results}

\section{Behavioral testing and skin temperature}

Baseline thresholds

Baseline values for heat, mechanical and cold sensitivity, as well as skin temperature pooled for both sides did not differ between $5-\mathrm{HTT}+/+$ and 5-HTT $-/-$ mice $(n=10-13$ each) (Table 1$)$. 

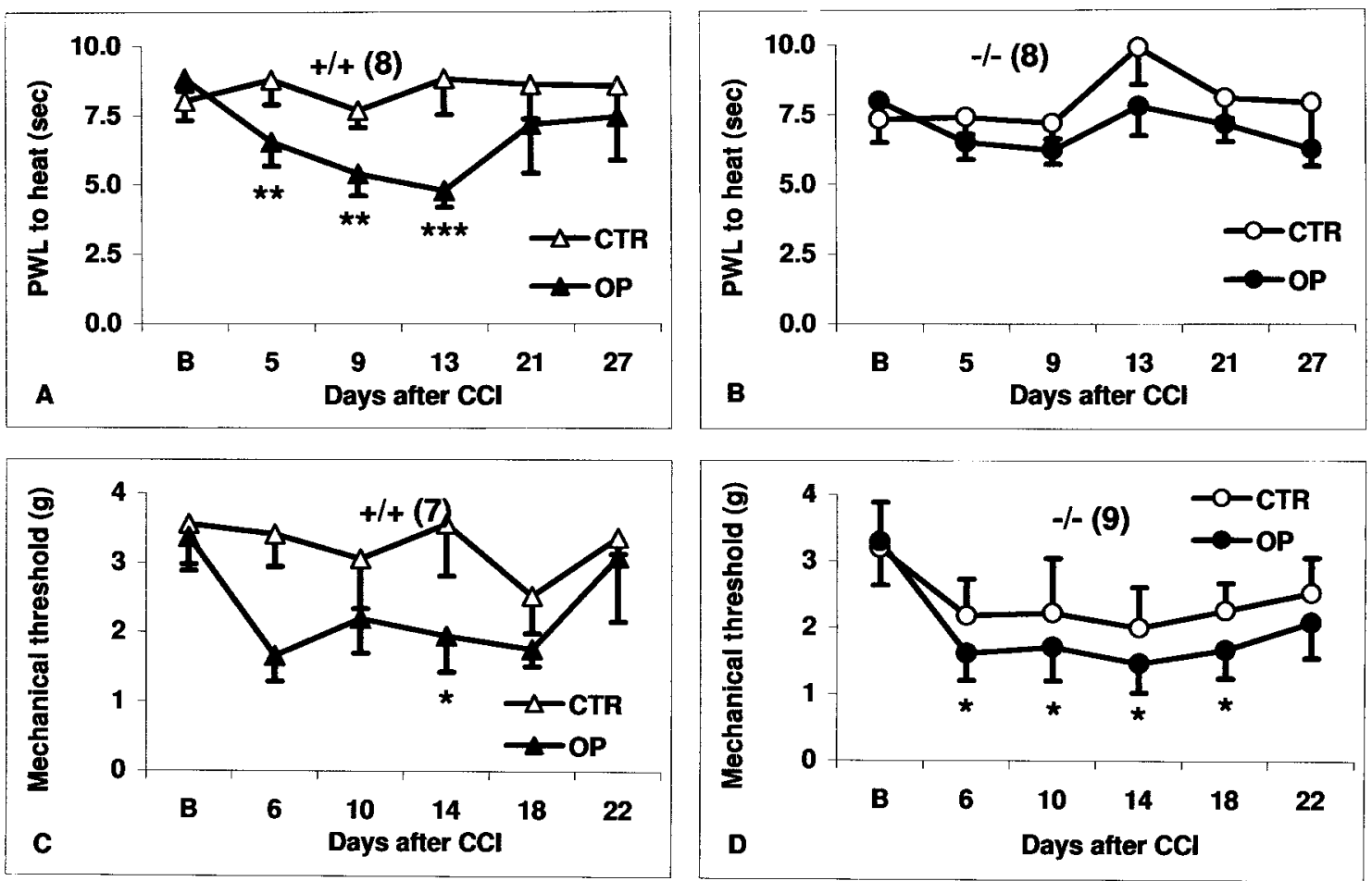

Figure 1. Mean PWLs to heat $(A, B)$ and mechanical $50 \%(C, D)$ thresholds at baseline $(B)$ and on distinct days after $C(\mathrm{Cl}$ in 5 -HTT $+/+(A, C)$ and $5-\mathrm{HTT}-/-$ mice $(B, D)$. Data are shown separately for the control (CTR) and the CCI [operated (OP)] side. $A, B, 0$ n the operated side, PWLs to heat are significantly reduced after $C(\mathrm{C}$ compared with the baseline in $+/+$ mice (heat hyperalgesia) but not in $-I-$ mice (no heat hyperalgesia). C, D, Mechanical thresholds on the operated side are significantly reduced after CCI compared with the baseline (mechanical allodynia) in both genotypes. There is also a trend to mechanical allodynia on the control side of $5-\mathrm{HTT}-1-$ mice. Values are expressed as the means \pm SEM of all animals tested (numbers shown in parentheses); ${ }^{*} p<0.05$; ${ }^{* *} p<0.005 ;{ }^{* * *} p<0.001$ versus baseline.

\section{CCI}

Heat hyperalgesia was observed on the CCI side in wild-type mice $(n=8)$ from the first to the end of the second postoperative week (Fig. 1A). PWLs decreased from $8.8 \pm 0.5 \mathrm{sec}$ at baseline to a minimum of $4.8 \pm 0.6 \sec (54.5 \%$ of baseline; $p<0.005)$ on day 13 and increased again on the subsequent days to values reaching the baseline level (Fig. $1 \mathrm{~A}$ ). No heat hyperalgesia was observed on the CCI side in 5-HTT $-/-$ mice $(n=8)$ throughout the observation period (Fig. $1 \mathrm{~B}$ ). On the side contralateral to $\mathrm{CCI}$, postoperative withdrawal latencies to heat in both genotypes did not differ from the baseline (Fig. 1A,B). Likewise, withdrawal latencies to heat in controls of both genotypes were not changed compared with the baseline after repetitive testing over 4 weeks (data not shown).

Mechanical allodynia was observed on the CCI side in all wildtype mice $(n=7)$ and 5-HTT- $-1-$ mice $(n=9)$ (Fig. $1 C, D)$. In wild-type mice, mechanical $50 \%$ thresholds on the contralateral side did not differ from the baseline (Fig. 1C). Mean thresholds on the contralateral side in 5-HTT $-/-$ mice had a trend toward a decrease after CCI that was not significant because of the high variability between animals (Fig. $1 D$ ). When individual thresholds were analyzed setting a limit of $\leq 1 \mathrm{gm}$ for the detection of mechanical allodynia, significantly more 5-HTT $-/-$ mice had contralateral mechanical allodynia than did $\mathrm{HTT}+/+$ mice $(p<0.01$ at days $6,14,18$, and 22). Unoperated mice of both genotypes did not develop reduced mechanical thresholds when repetitively tested over a period of 4 weeks (data not shown).

The withdrawal time of the hindpaw to acetone in control mice of both genotypes during repetitive testing did not deviate from the baseline (data not shown). Similarly, on the con- tralateral side of CCI-operated mice of each genotype, the withdrawal time to acetone did not change from baseline. An increased withdrawal time to acetone, cold allodynia, was observed on the CCI side in four of eight wild-type mice and in three of seven 5-HTT $-1-$ mice tested $(p<0.05$ compared with baseline) (Fig. $2 A, B$ ). In the other cases of both genotypes, the withdrawal times on the CCI side were unchanged compared with baseline (Fig. $2 C, D$ ). In summary, the incidence and extent of cold allodynia were not different between genotypes.

After CCI, skin temperature asymmetry between both hindpaws was observed in four of nine $5-\mathrm{HTT}+/+$ mice and five of nine-5-HTT $-/-$ mice (Fig. 3 ). In three 5 -HTT $+/+$ mice and in five 5-HTT-/- mice, the hindpaw on the side of CCI was warmer than the unoperated side (positive difference score in Fig. $3 A, B$ ); in one 5 -HTT $+/+$ mouse it was colder (negative difference score in Fig. 3A). Furthermore, temperatures varied over time. In both genotypes, skin temperatures were maximal on day 9. In summary, the incidence of skin temperature changes was the same in both genotypes. The controls of each genotype did not show any change in skin temperature after repetitive testing.

\section{5-HT and 5-HIAA content in nervous tissue and adrenal glands}

\section{5-HT}

Controls. Under normal conditions, 5-HT was detectable in both genotypes in the sciatic nerve, plantar skin, lumbar spinal cord, and adrenal glands. The 5-HT content was significantly lower in 

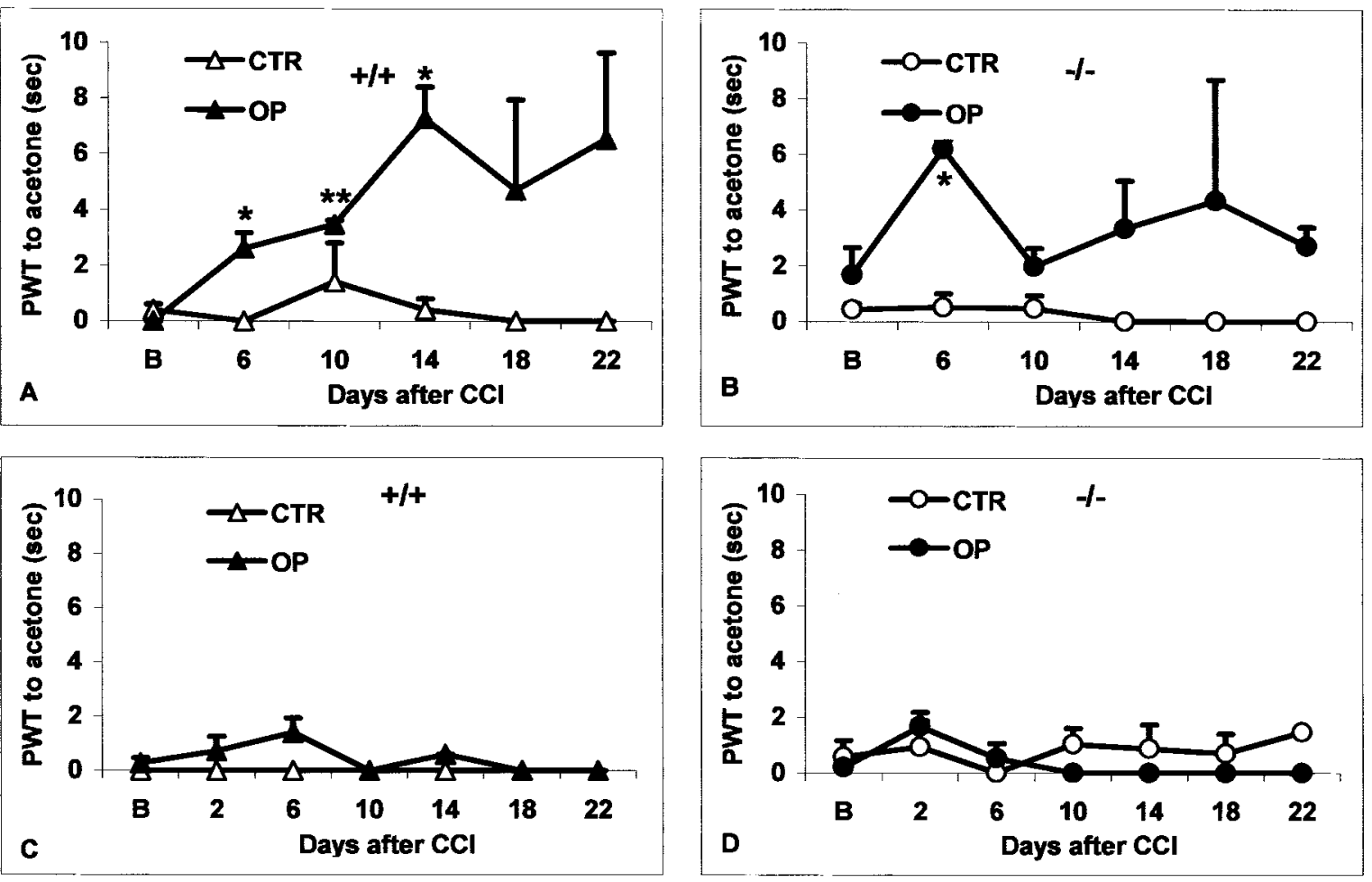

Figure 2. Paw withdrawal time (PWT) to acetone shown in two 5-HTT $+/+$ mice $(A, C)$ and in two $5-\mathrm{HTT}-/-$ mice $(B, D)$ at baseline $(B)$ and on distinct days after $C \mathrm{Cl}$. Data are presented separately for the control (CTR) and the operated (OP) side. On the operated side, individual animals of both genotypes could postoperatively show either a significant increase (cold allodynia, $A, B$ ) or no change in the PWT to acetone compared with the baseline $(C, D) .{ }^{*} p<0.05 ;{ }^{* *} p<0.005$ versus baseline.
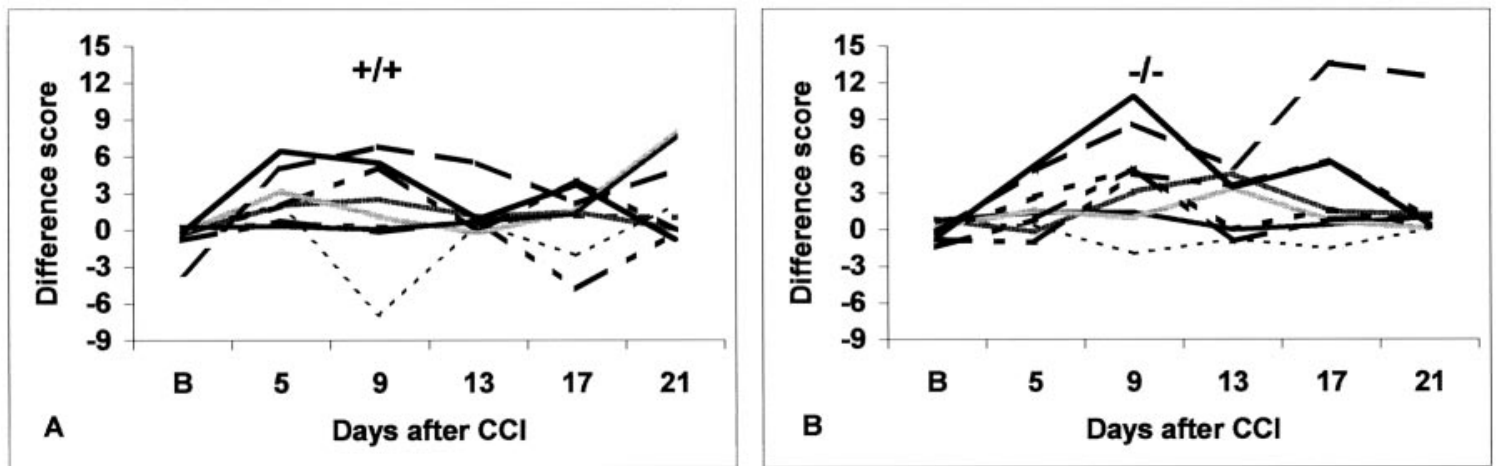

Figure 3. Skin temperature differences between both hindpaws at baseline and on distinct days after $\mathrm{CCl}$ in $5-\mathrm{HTT}+/+$ mice $(A)$ and $5-\mathrm{HTT}-/-$ mice $(B)$. Individual difference scores (temperature on the C(I side - temperature on the control side) of all of the animals tested ( $n=9$ for each genotype) are shown.

all tissues of 5-HTT-/- mice compared with wild-type mice $(p<0.05)$ (Fig. 4, Table 2).

CCI. At 13 and $28 \mathrm{~d}$ after CCI, wild-type mice had a significant increase in 5-HT in the operated sciatic nerve $(p<0.05$ compared with controls) (Fig. 4 A, Table 2 ) with a maximum of $354 \%$ on day 28. In 5-HTT-/- mice, the 5-HT concentration in the operated nerve was not changed on day 13 but increased on day 28 after CCI compared with controls $(p<0.05)$ (Fig. $4 A$, Table 2). The relative increase over controls was comparable with 5 -HTT $+/+$ mice, although absolute values were lower. Between genotypes, the operated and the contralateral nerve (day 28) contained significantly more 5-HT in wild-type mice than in 5 -HTT $-/-$ mice $(p<0.05)$ (Fig. $4 A$, Table 2$)$. The 5 -HT concentration in the plantar skin was slightly reduced bilaterally after CCI in wild-type animals $(p<0.05$ for the contralateral side) (Fig. $4 B$, Table 2). Except on postoperative day 28, 5-HT concentrations in 5-HTT $-/-$ mice were lower than in wild-type mice.

The 5-HT content of the L4/5 spinal cord was reduced in wild-type mice compared with controls on days 13 and 28 after CCI $(p<0.05)$ (Fig. $4 C$, Table 2$)$. In 5 -HTT $-/-$ mice, the reduction was almost significant at day $28(p=0.06)$. Between genotypes, the lumbar spinal cord of operated animals contained significantly more 5-HT in wild-type mice than knock-out animals $(p<0.05)$ (Fig. 4C, Table 2).

In the adrenal glands of wild-type mice, 5 -HT was reduced to $64 \%$ compared with controls on day 13 after CCI $(p<0.05)$. In 5 -HTT-/- mice, the 5-HT concentration was significantly lower than in wild-type mice $(p<0.001)$ with no changes after CCI (Fig. $4 D$, Table 2).

In summary, in all tissues from unoperated mice, the 5-HT content was higher in wild-type than in knock-out mice. After 

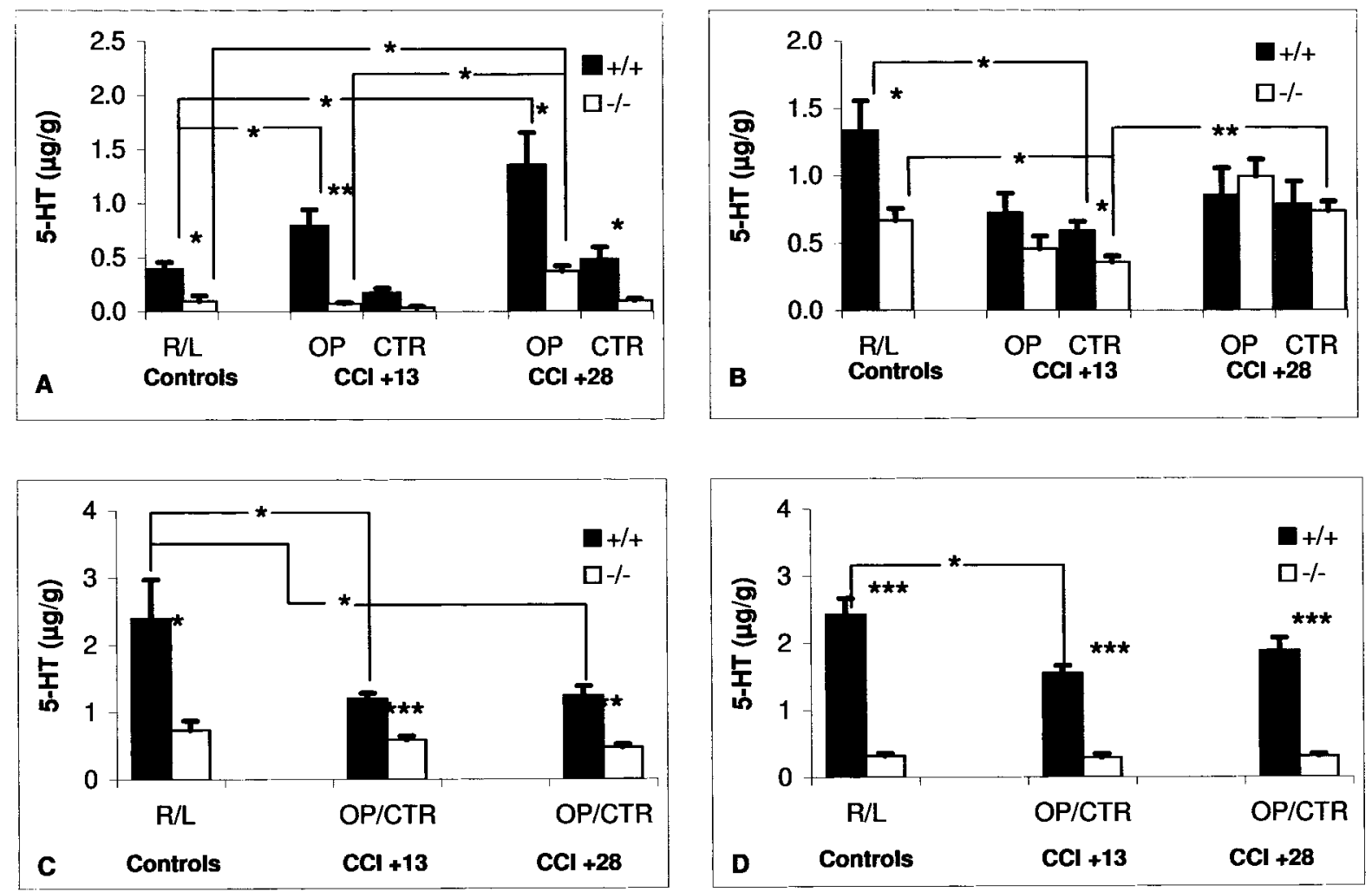

Figure 4. 5-HT concentration in micrograms per gram of wet tissue in different tissues of unoperated (controls) and operated wild-type mice $(+/+)$ and $5-\mathrm{HTT}-/-$ mice $(-/-)$ on day 13 $(C \mathrm{Cl}+13)$ and day 28 after $\mathrm{Cl}(\mathrm{CCl}+28)$. In the sciatic nerve $(A)$ and the plantar skin $(B)$, data obtained from each side are pooled in controls [right $(R) /$ left $(L)]$ and shown separately for the operated (OP) side and the control (CTR) side in animals with CCI. In the lumbar spinal cord ( $C$ and the adrenal glands ( $D$ ), data were obtained from both sides (R/L, OP/CTR). Data are shown as means \pm SEM; ${ }^{*} p<0.05 ;{ }^{* *} p<0.005 ;{ }^{* * *} p<0.001$.

Table 2. Mean 5-HT concentration in different nervous tissues and adrenal glands in $5-\mathrm{HTT}+/+$ mice $(+/+)$ and $5-\mathrm{HTT}-/-$ mice $(-/-)$

\begin{tabular}{|c|c|c|c|c|c|c|c|c|}
\hline & $\begin{array}{l}\text { Sciatic nerve } \\
+/+\end{array}$ & $-1-$ & $\begin{array}{l}\text { Plantar skin } \\
+/+\end{array}$ & $-1-$ & $\begin{array}{l}\text { L4/5 spinal cord } \\
+/+\end{array}$ & $-1-$ & $\begin{array}{l}\text { Adrenal glands } \\
+/+\end{array}$ & $-1-$ \\
\hline $\begin{array}{l}\text { Controls (right/left) }(\mu \mathrm{g} / \mathrm{gm}) \\
\mathrm{Cl}+13(\mu / \mathrm{gm})\end{array}$ & $0.4 \pm 0.1(10)$ & $0.1 \pm 0.1(4)$ & $1.3 \pm 0.2(9)$ & $0.7 \pm 0.1(7)$ & $2.4 \pm 0.6(10)$ & $0.7 \pm 0.1(7)$ & $2.4 \pm 0.2(7)$ & $0.3 \pm 0.0(7)$ \\
\hline$O P$ & $0.8 \pm 0.2$ & $0.1 \pm 0.0$ & $0.7 \pm 0.1$ & $0.5 \pm 0.1$ & & & & \\
\hline $\begin{array}{c}\text { CTR } \\
\mathrm{CCl}+28(\mu \mathrm{g} / \mathrm{gm})\end{array}$ & $0.2 \pm 0.1(7)$ & $0.0 \pm 0.0(5)$ & $0.6 \pm 0.1(7)$ & $0.4 \pm 0.0(5)$ & $1.2 \pm 0.1(9)$ & $0.6 \pm 0.1(9)$ & $1.6 \pm 0.1(7)$ & $0.3 \pm 0.1(5)$ \\
\hline$O P$ & $1.4 \pm 0.3$ & $0.4 \pm 0.1$ & $0.9 \pm 0.2$ & $1.0 \pm 0.1$ & & & & \\
\hline CTR & $0.5 \pm 0.1(9)$ & $0.1 \pm 0.0(9)$ & $0.8 \pm 0.2(7)$ & $0.7 \pm 0.1(8)$ & $1.2 \pm 0.2(7)$ & $0.5 \pm 0.0(5)$ & $1.9 \pm 0.2(9)$ & $0.3 \pm 0.00(9)$ \\
\hline
\end{tabular}

Data are pooled for both sides (right/left) in unoperated animals (controls). On days 13 and 28 after $\mathrm{ClI}(\mathrm{CCl}+13$ and $\mathrm{Cl}+28$ ), values of the sciatic nerve and the plantar skin are evaluated separately on the operated (OP) and contralateral nonoperated side (CTR); values of the L4/5 spinal cord and the adrenal glands are recruited from both sides. Data are given as means \pm SEM. The number of animals tested is shown in parentheses. Also see Figure 4 .

CCI, the 5-HT content increased in the operated sciatic nerve in both genotypes, whereas it decreased in wild-type mice in the lumbar spinal cord and in the adrenal glands.

\section{5-HIAA}

5-HIAA data mirrored the 5-HT data, with an increase after CCI in the sciatic nerve and a decrease in spinal cord and in skin. With a trend toward a higher 5-HIAA content in wild-type mice, differences between genotypes were not significant in most tissues (Fig. 5).

\section{Discussion}

After an incomplete sciatic nerve injury, 5-HTT-/-mice differed from their littermate controls by a lack of thermal hyperalgesia and by the development of bilateral rather than unilateral mechanical allodynia. 5-HT levels were lower in 5-HTT - / - mice than in wild-type mice in all tissues examined. Interestingly,
5-HT was increased in the injured nerve in both genotypes but decreased in the spinal cord after nerve injury in wild-type mice.

5-HTT -/- mice do not develop thermal hyperalgesia after CCI, but do develop bilateral mechanical allodynia

Nociceptive nerve fibers can be excited and sensitized by inflammatory mediators, including 5-HT (Beck and Handwerker, 1974; Handwerker and Reeh, 1991). This normally takes place at the receptor site on the sensory terminal (Raja et al., 1999). After nerve lesion, the injured axons themselves can be activated and sensitized by inflammatory mediators (Welk et al., 1990; Michaelis et al., 1997, 1998). We hypothesize that 5-HT in the injured nerve sensitizes nociceptive nerve fibers to heat stimuli, thus leading to heat hyperalgesia, and that the low 5-HT concentration in 5 -HTT $-/-$ mice is the reason for the lack of heat hyperalgesia in these mice.

Punctate mechanical allodynia as shown in the CCI model 

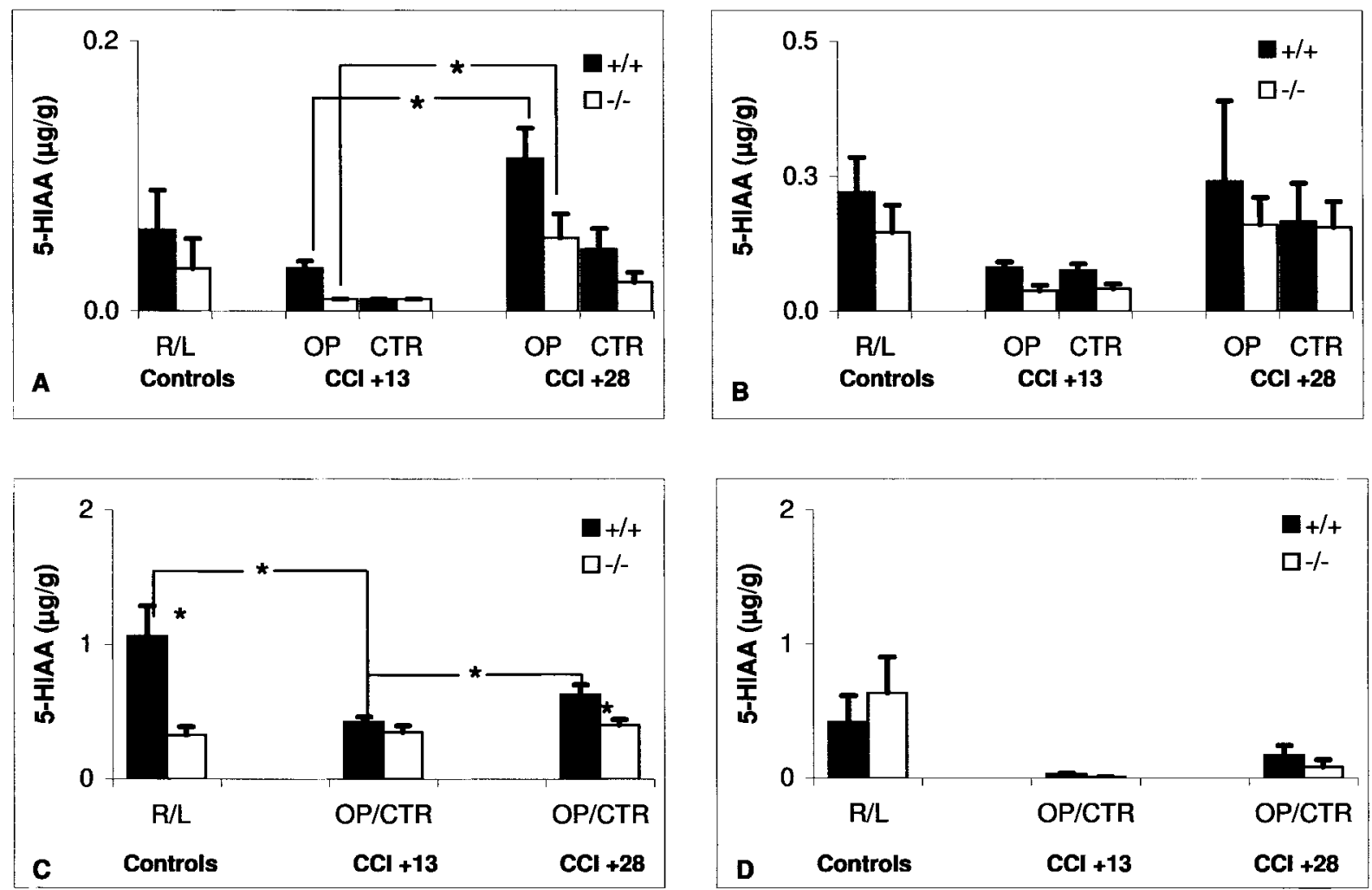

Figure 5. Concentration of 5-HIAA in micrograms per gram of wet tissue in different tissues $(A-D)$ of unoperated and operated wild-type and 5 - $\mathrm{HTT}-/-$ mice $(-/-)$ on day $13(C \mathrm{Cl}+13)$ and day 28 after $C \mathrm{CI}(C \mathrm{Cl}+28)$. In the sciatic nerve $(A)$ and the plantar skin $(B)$, data obtained from each side are pooled for the right and left $(R / L)$ side in controls and are shown separately for the operated (OP) side and the control (CTR) side in animals with CCI. In the lumbar spinal cord ( $C$ and the adrenal glands ( $D)$, data were obtained from both sides. Data are shown as means \pm SEM; ${ }^{*} p<0.05$.

may be mediated by A $\delta$ fibers (Field et al., 1999). The development of mechanical allodynia depends on changes in spinal connectivity (i.e., central sensitization). Various mechanisms have been implicated in the development of central sensitization, including the loss of descending inhibition at the spinal cord level. Spinal 5-HT is analgesic in most paradigms through an action at spinal $5-\mathrm{HT}_{2 \mathrm{~A}}$ and $5-\mathrm{HT}_{3}$ receptors (Solomon and Gebhart, 1988; Oyama et al., 1996), although some studies describe a pronociceptive action of 5-HT or its agonists (Eide and Hole, 1988, Ali et al., 1996). Spinal 5-HT is reduced after CCI in wildtype mice, and baseline and post-CCI levels in 5-HTT-/- mice are lower than in wild-type mice. Assuming that spinal 5-HT in wild-type mice has an inhibitory action on pain transmission, the bilateral allodynia in 5 -HTT $-/-$ mice may be explained by a reduced spinal inhibition attributable to a lack of spinal 5-HT. The phenomenon of bilateral hyperalgesia or allodynia after unilateral nerve injury has been described occasionally (Attal et al., 1994) and is usually explained by signaling via commissural interneurons or by chemical signals, for example growth factors (Koltzenburg et al., 1999). However, in our previous experiments with unilateral CCI in wild-type mice and rats, we never observed contralateral pain-related behavior. Interestingly, Esser and Sawynok (1999) found that animals with mechanical allodynia on the side ipsilateral to a nerve lesion developed contralateral allodynia after the application of amitriptyline. Thus, the lack of spinal inhibition might account for the bilateral allodynia observed in 5 -HTT $-/-$ mice in the present experiment.

In contrast to heat hyperalgesia and mechanical allodynia, cold allodynia and skin temperature changes after CCI were very variable between animals and were independent of genotype.
Wakisaka et al. (1991) found skin temperature changes in 75\% of their rats with CCI and observed a trend over time from too hot to too cold. In our mice, a trend toward normalization was observed toward the end of the experiment. In the rat model of spinal nerve ligation, systemic application of the indirect 5-HT agonist fenfluramine but not of amitriptyline or desipramine acutely reduced cold allodynia (Wang et al., 1999). From our results, it cannot be concluded that chronic blockade of serotonin reuptake has a major influence on the development of cold allodynia. However, because of the high variability in these data, the number of animals may be too small to reveal differences between genotypes.

Tissue 5-HT levels are reduced in 5-HTT $-/-$ mice

In all tissues examined, naive $5-\mathrm{HTT}-/-$ mice had lower levels of 5-HT than naive 5-HTT $+/+$ mice. This difference was most marked in the adrenal glands. In the periphery, $5-\mathrm{HT}$ is produced by enterochromaffin cells and transported into the tissues by platelets and mast cells. 5-HT is unable to penetrate the bloodbrain and blood-nerve barrier, but a small amount of 5-HT is produced in neuronal cells and their terminals. The 5-HTT is needed for uptake of 5-HT into the cells. Thus, a functionally ablated 5-HTT in 5-HTT- $/-$ mice entails reduced tissue 5-HT concentrations. In addition, as evidenced by the trend toward an increase in the 5-HIAA concentration in adrenal glands, adaptive changes in 5-HT metabolism with an exaggerated catabolism may account for the substantial depletion of 5-HT.

The 5-HT concentrations we determined in different tissues of naive wild-type mice are comparable with other data from naive rodents. Thus, the normal sciatic nerve in the rat contains $\sim 0.5 \mu$ g of 5 -HT per gram of wet tissue (Anden and Olsson, 
1967), which is identical to our data. The same 5-HT content was determined in the lumbar spinal cord of rats (Satoh and Omote, 1996), which is considerably lower than that found by us $(2.4 \mu \mathrm{g}$ per gram of wet tissue). Previous studies showed that naive 5 -HTT $-/-$ mice have a $60-80 \%$ reduction in 5-HT concentrations in different brain areas (Bengel et al., 1998). Similarly, we found reductions in 5-HT concentrations in all tissues examined, with reductions between 50\% in plantar skin and $90 \%$ in adrenal glands.

In 5 -HTT $-/-$ mice, reductions in the entire $5-\mathrm{HT}$ concentration in different tissues did not result in altered pain-related behavior in naive animals but did result in altered pain-related behavior after CCI. This suggests a role for 5-HT in nociceptive transmission after nerve injury that is different from the one in the naive animal.

\section{CCI induces increased 5-HT levels in the injured nerve}

Four weeks after CCI in wild-type mice, the 5-HT concentration in the injured nerve was increased to $\sim 300 \%$ of the control value. Similar increases in 5-HT concentration have been detected in rat sciatic nerve 4 weeks after axotomy (Anden and Olsson, 1967). In contrast, the 5-HT concentration in the lumbar spinal cord was decreased, with reductions to $50 \%$ of the control value. In the same model of nerve injury in the rat, others found an increase in the spinal 5-HT concentration within the first 2 weeks after nerve lesions and no change in the third and forth postoperative week (Satoh and Omote, 1996). A possible reason for this discrepancy may be that the 5-HT concentration in the study of Satoh and Omote (1996) was determined in the dorsal half of one side of the lumbar spinal cord, whereas we analyzed the complete transverse section.

Because injury of the sciatic nerve may result in a neurogenic inflammatory response of the plantar skin (Levine et al., 1990; Daemen et al., 1998), we had expected major changes in the 5-HT concentration in this tissue after CCI. However, this was not the case. In the adrenal glands, which have been suggested to have an influence on nociception in different pain models (Hama and Sagan, 1993; Khasar et al., 1998; Hains et al., 2000), there was a CCI-induced reduction of 5-HT in wild-type mice. This finding also supports the notion of a possible role of the adrenal glands in nociceptive transmission.

\section{5-HTT $-/-$ mice as a model of chronic treatment with SSRI}

5-HTT-/- mice have been regarded as a model of chronic pharmacological blockade of 5-HT reuptake (Bengel et al., 1998). Of the SSRIs, only fluoxetine and fenfluramine have been investigated in animal models of neuropathic pain, and except for the effect of fenfluramine on cold allodynia, they have not been found effective (Jett et al., 1997; Sawynok et al., 1999; Wang et al., 1999). Thus, a direct comparison of pharmacological studies with the present data is not possible. Interestingly, TCAs in animal models produce a consistent antinociceptive effect on heat hyperalgesia (Lang et al., 1996; Esser and Sawynok, 1999; Sawynok et al., 1999) but not on mechanical (Esser et al., 1999; Wang et al., 1999) and cold allodynia (Wang et al., 1999). This pattern is in line with our findings in 5 -HTT $-/-$ mice and may suggest an antinociceptive effect of TCAs via inhibition of 5-HT reuptake in the peripheral nervous system. However, several other modes of action of TCAs, such as the blockade of sodium channels, may be involved (Gerner et al., 2001).

The 5-HT receptors $5-\mathrm{HT}_{1 \mathrm{~A}}, 5-\mathrm{HT}_{1 \mathrm{~B}}$, and $5-\mathrm{HT}_{2 \mathrm{~A}}$ are downregulated in 5-HTT-/- mice (Rioux et al., 1999; Fabre et al., 2000). An influence of this receptor plasticity on our behavioral results cannot be ruled out. However, whether $5-\mathrm{HT}_{2 \mathrm{~A}}$ receptors are also downregulated in the periphery is not known. If this were the case, it could be another explanation for reduced hyperalgesia of peripheral origin in 5-HTT-/- mice (Obata et al., 2000).

In conclusion, our results suggest a peripheral pronociceptive role of 5-HT in the injured nerve in neuropathic pain. This sheds new light on the possible mechanisms by which serotonergic systems might be involved in nociception after nerve injury. Furthermore, the correlation of nerve 5-HT levels to heat hyperalgesia, but not to mechanical and cold allodynia, reveals distinct mechanisms underlying the different forms of neuropathic pain.

\section{References}

Abad F, Feria M, Boada J (1989) Chronic amitriptyline decreases autonomy following dorsal rhizotomy in rats. Neurosci Lett 99:187-190.

Abdi S, Lee DH, Chung JM (1998) The anti-allodynic effects of amitriptyline, gabapentin, and lidocaine in a rat model of neuropathic pain. Anesth Analg 87:1360-1366.

Ali Z, Wu G, Kozlov A, Barasi S (1996) The role of 5HT3 in nociceptive processing in the rat spinal cord: results from behavioural and electrophysiological studies. Neurosci Lett 208:203-207.

Anden NE, Olsson Y (1967) 5-Hydroxytryptamine in normal and sectioned rat sciatic nerve. Acta Pathol Microbiol Scand 70:537-540.

Ardid D, Guilbaud G (1992) Antinociceptive effects of acute and "chronic" injections of tricyclic antidepressant drugs in a new model of mononeuropathy in rats. Pain 49:279-287.

Attal N, Filliatreau G, Perrot S, Jazat F, Di Giamberardino L, Guilbaud G (1994) Behavioural pain-related disorders and contribution of the saphenous nerve in crush and chronic constriction injury of the rat sciatic nerve. Pain 59:301-312.

Beck PW, Handwerker HO (1974) Bradykinin and serotonin effects on various types of cutaneous nerve fibres. Pflügers Arch 347:209-222.

Bengel D, Murphy DL, Andrews AM, Wichems CH, Feltner D, Heils A, Mössner R, Westphal H, Lesch KP (1998) Altered brain serotonin homeostasis and locomotor insensitivity to 3,4-methylenedioxymethamphetamine ("Ecstasy") in serotonin transporter-deficient mice. Mol Pharmacol 53:649-655.

Bennett GJ, Xie YK (1988) A peripheral mononeuropathy in rat that produces disorders of pain sensation like those seen in man. Pain 33:87-107.

Carlton SM, Coggeshall RE (1997) Immunohistochemical localization of $5-\mathrm{HT}_{2 \mathrm{~A}}$ receptors in peripheral sensory axons in rat glabrous skin. Brain Res 763:271-275.

Chaplan SR, Bach FW, Pogrel JW, Chung JM, Yaksh TL (1994) Quantitative assessment of tactile allodynia in the rat paw. J Neurosci Methods 53:55-63.

Choi Y, Yoon YW, Na HS, Kim SH, Chung JM (1994) Behavioral signs of ongoing pain and cold allodynia in a rat model of neuropathic pain. Pain 59:369-376.

Daemen M, Kurvers H, Bullens P, Barendse G, Van Kleef M, Van den Wildenberg F (1998) Neurogenic inflammation and reflex sympathetic dystrophy (in vivo and in vitro assessment in an experimental model). Acta Orthop Belg 64:441-447.

Dixon W (1965) The up-and-down method for small samples. J Am Stat Assoc 60:967-978.

Eide PK, Hole K (1988) Increased behavioural response to intrathecal serotonin after lesion of serotonergic pathways with 5,7-dihydroxytryptamine seems not to be due to depletion of serotonin. Acta Physiol Scand 134:291-294.

Eide PK, Hole K (1993) The role of 5-hydroxytryptamine (5-HT) receptor subtypes and plasticity in the 5-HT systems in the regulation of nociceptive sensitivity. Cephalalgia 13:75-85.

Eschalier A, Mestre C, Dubrya C, Ardid D (1994) Why are antidepressants effective as pain relief? CNS Drugs 2:261-267.

Esser MJ, Sawynok J (1999) Acute amitriptyline in a rat model of neuropathic pain: differential symptom and route effects. Pain 80:643-653.

Fabre V, Beaufour C, Evrard A, Rioux A, Hanoun N, Lesch KP, Murphy DL, Lanfumey L, Hamon M, Martres M-P (2000) Altered expression and functions of serotonin 5- $\mathrm{HT}_{1 \mathrm{~A}}$ and $5-\mathrm{HT}_{1 \mathrm{~B}}$ receptors in knock-out mice lacking the 5-HT transporter. Eur J Neurosci 12:2299-2310.

Field MJ, Bramwell S, Hughes J, Singh L (1999) Detection of static and dynamic components of mechanical allodynia in rat models of neuro- 
pathic pain: are they signalled by distinct primary sensory neurones? Pain 83:303-311.

Fozard JR (1984) Neuronal 5-HT receptors in the periphery. Neuropharmacology 23:1473-1486.

Gerner P, Mujtaba M, Sinnott CJ, Wang GK (2001) Amitriptyline versus bupivacaine in rat sciatic nerve blockade. Anesthesiology 94:661-667.

Hains BC, Chastain KM, Everhart AW, McAdoo DJ, Hulsebosch CE (2000) Transplants of adrenal medullary chromaffin cells reduce forelimb and hindlimb allodynia in a rodent model of chronic central pain after spinal cord hemisection injury. Exp Neurol 164:426-437.

Hama AT, Sagan J (1993) Reduced pain-related behavior by adrenal medullary transplants in rats with experimental painful peripheral neuropathy. Pain 52:223-231.

Handwerker HO, Reeh PW (1991) Pain and inflammation. In: Proceedings of the Sixth World Congress on Pain (Bond MR, Charlton JE, Woolf CJ, eds), p 59. Amsterdam: Elsevier.

Hargreaves K, Dubner R, Brown F, Flores C, Joris J (1988) A new and sensitive method for measuring thermal nociception in cutaneous hyperalgesia. Pain 32:77-88.

Jett MF, McGuirk J, Waligora D, Hunter JC (1997) The effects of mexiletine, desipramine, and fluoxetine in rat models involving central sensitization. Pain 69:161-169.

Khasar SG, Miao FJ, Janig W, Levine JD (1998) Vagotomy-induced enhancement of mechanical hyperalgesia in the rat is sympathoadrenalmediated. J Neurosci 18:3043-3049.

Koltzenburg M, Wall PD, McMahon SB (1999) Does the right side know what the left is doing? Trends Neurosci 22:122-127.

Lang E, Hord AH, Denson D (1996) Venlafaxine hydrochloride (Effexor ${ }^{\mathrm{TM}}$ ) relieves thermal hyperalgesia in rats with an experimental mononeuropathy. Pain 68:151-155.

Lesch KP, Heils A (2000) Serotonergic gene transcriptional control regions: targets for antidepressant drug development? Int J Neuropsychopharmacol 3:67-79.

Levine JD, Coderre TJ, White DM, Finkbeiner WE, Basbaum AI (1990) Denervation-induced inflammation in the rat. Neurosci Lett 119:37-40.

Michaelis M, Vogel C, Blenk K-H, Jänig W (1997) Algesics excite axotomized afferent nerve fibres within the first hours following nerve transection in rats. Pain 72:347-354.

Michaelis M, Vogel C, Blenk K-H, Arnarson A, Jänig W (1998) Inflammatory mediators sensitize acutely axotomized nerve fibers to mechanical stimulation in the rat. J Neurosci 18:7581-7587.

Obata H, Saito S, Ishizaki K, Goto F (2000) Antinociception in rat by sarpogrelate, a selective 5-HT(2A) receptor antagonist, is peripheral. Eur J Pharmacol 404:95-102.
Oyama T, Ueda M, Kuraishi Y, Akaike A, Satoh M (1996) Dual effect of serotonin on formalin-induced nociception in the rat spinal cord. Neurosci Res 25:129-135.

Raja SN, Meyer RA, Ringkamp M, Campbell JN (1999) Peripheral neural mechanisms of nociception. In: Textbook of pain, Ed 4 (Wall PD, Melzack R, eds), pp 11-57. London: Churchill Livingstone.

Rioux A, Fabre V, Lesch KP, Moessner R, Murphy DL, Lanfumey L, Hamon M, Martres M-P (1999) Adaptive changes of serotonin 5- $\mathrm{HT}_{2 \mathrm{~A}}$ receptors in mice lacking the serotonin transporter. Neurosci Lett 262:113-116.

Satoh O, Omote K (1996) Roles of monoaminergic, glycinergic, and GABAergic inhibitory systems in the spinal cord in rats with peripheral mononeuropathy. Brain Res 728:27-36.

Sawynok J, Esser MJ, Reid AR (1999) Peripheral antinociceptive actions of desipramine and fluoxetine in an inflammatory and neuropathic pain test in the rat. Pain 82:149-158.

Seltzer Z, Tal M, Sharay Y (1989) Autonomy behavior in rats following peripheral deafferentiation is suppressed by daily injections of amitriptyline, diazepam, and saline. Pain 37:245-250.

Sindrup SH, Gram LF, Brosen K, Eshoj O, Mogensen EF (1990) The selective serotonin reuptake inhibitor paroxetine is effective in the treatment of diabetic neuropathy symptoms. Pain 42:135-144.

Sindrup SH, Bjerre U, Dejgaard A, Brosen K, Aaes-Jorgensen T, Gram LF (1992) The selective serotonin reuptake inhibitor citalopram relieves the symptoms of diabetic neuropathy. Clin Pharmacol Ther 52:547-552.

Solomon RE, Gebhart GF (1988) Mechanisms of effects of intrathecal serotonin on nociception and blood pressure in rats. J Pharmacol Exp Ther 245:905-912.

Sommer C, Schäfers M (1998) Painful mononeuropathy in C57Bl/Wld mice with delayed Wallerian degeneration: differential effects of cytokine production and nerve regeneration on thermal and mechanical hypersensitivity. Brain Res 784:154-162.

Vogel C, Lindenlaub T, Tiegs G, Toyka KV, Sommer C (2000) Pain-related behavior in TNF-receptor-deficient mice. In: Proceedings of the Ninth World Congress on Pain (Devor M, Rowbotham MC, Wiesenfeld-Hallin Z, eds), pp 249-257. Seattle: International Association for the Study of Pain.

Wakisaka S, Kajander KC, Bennett GJ (1991) Abnormal skin temperature and abnormal sympathetic vasomotor innervation in an experimental painful peripheral neuropathy. Pain 46:299-313.

Wang YX, Bowersox SS, Pettus M, Gao D (1999) Antinociceptive properties of fenfluramine, a serotonin reuptake inhibitor, in a rat model of neuropathy. J Pharmacol Exp Ther 291:1008-1016.

Welk E, Leah JD, Zimmermann M (1990) Characteristics of A- and Cfibres ending in a sensory nerve neuroma in the rat. J Neurophysiol $63: 759-766$. 